\title{
Streamflow forecast sensitivity to air temperature forecast calibration for 139 Norwegian catchments
}

\author{
Trine J. Hegdahl ${ }^{1}$, Kolbjørn Engeland ${ }^{1,2}$, Ingelin Steinsland ${ }^{3}$, and Lena M. Tallaksen ${ }^{2}$ \\ ${ }^{1}$ Department of Hydrology, Norwegian Water Resources and Energy Directorate, 0301 Oslo, Norway \\ ${ }^{2}$ Department of Geosciences, University of Oslo, 0316 Oslo, Norway \\ ${ }^{3}$ Department of Mathematical Sciences, Norwegian University of Science and Technology, 7034 Trondheim, Norway
}

Correspondence: Trine J. Hegdahl (tjh@nve.no)

Received: 5 July 2018 - Discussion started: 31 July 2018

Revised: 11 January 2019 - Accepted: 16 January 2019 - Published: 7 February 2019

\begin{abstract}
In this study, we used meteorological ensemble forecasts as input to hydrological models to quantify the uncertainty in forecasted streamflow, with a particular focus on the effect of temperature forecast calibration on the streamflow ensemble forecast skill. In catchments with seasonal snow cover, snowmelt is an important flood-generating process. Hence, high-quality air temperature data are important to accurately forecast streamflows. The sensitivity of streamflow ensemble forecasts to the calibration of temperature ensemble forecasts was investigated using ensemble forecasts of temperature from the European Centre for Medium-Range Weather Forecasts (ECMWF) covering a period of nearly 3 years, from 1 March 2013 to 31 December 2015. To improve the skill and reduce biases of the temperature ensembles, the Norwegian Meteorological Institute (MET Norway) provided parameters for ensemble calibration, derived using a standard quantile mapping method where HIRLAM, a high-resolution regional weather prediction model, was used as reference. A lumped HBV (Hydrologiska Byråns Vattenbalansavdelning) model, distributed on 10 elevation zones, was used to estimate the streamflow. The results show that temperature ensemble calibration affected both temperature and streamflow forecast skill, but differently depending on season and region. We found a close to $1: 1$ relationship between temperature and streamflow skill change for the spring season, whereas for autumn and winter large temperature skill improvements were not reflected in the streamflow forecasts to the same degree. This can be explained by streamflow being less affected by subzero temperature improvements, which accounted for the biggest temperature biases and corrections during autumn and winter. The skill differs
\end{abstract}

between regions. In particular, there is a cold bias in the forecasted temperature during autumn and winter along the coast, enabling a large improvement by calibration. The forecast skill was partly related to elevation differences and catchment area. Overall, it is evident that temperature forecasts are important for streamflow forecasts in climates with seasonal snow cover.

\section{Introduction}

Floods can severely damage infrastructure, buildings, and farmland, and can have high economic impacts on society (Dobrovičová et al., 2015). Early warnings based on hydrometeorological forecasts are an important flood mitigation measure and provide time to reduce flood damage. A floodforecasting system consists of a hydro-meteorological forecasting chain with three main components, all affected by uncertainties: (i) observations used to establish the initial conditions for the catchment, (ii) meteorological forecasts used as forcing, and (iii) the hydrological model.

The Norwegian flood-forecasting system, operated by the Norwegian Water Resources and Energy Directorate (NVE), uses deterministic forecasts of air temperature and precipitation as forcing for hydrological models in 145 catchments across the country. Meteorological forecasts from the AROME-MetCoOp operational weather prediction model (Müller et al., 2017) are used for short-range forecasts (day 1 and 2), whereas forecasts from the European Centre for Medium-Range Weather Forecasts (ECMWF, 2018a) high-resolution model are used for medium-range forecasts 
(day 3 to 9). All forecasts are provided by the Norwegian Meteorological Institute (MET Norway). The Hydrologiska Byråns Vattenbalansavdelning model (HBV) (Bergström, 1976; Sælthun, 1996; Beldring, 2008) is used as the hydrological forecasting model, which combined with statistical uncertainty models (Langsrud et al., 1998, 1999) provides probabilistic streamflow forecasts. The uncertainty model accounts for the strong autocorrelation in forecast errors and estimates an uncertainty band around the deterministic temperature, precipitation, and streamflow forecasts.

An alternative approach to estimate probabilistic streamflow forecasts is to use meteorological ensemble forecasts from numerical weather prediction models as a means to account for uncertainty in the forcing. The meteorological ensemble forecasts are created by perturbing both the initial states and the physics tendencies of the original deterministic forecast. The spread of the ensemble members can be interpreted as the uncertainty of the forecasts, where a large spread indicates large uncertainty (Buizza et al., 1999; Persson, 2015). Subsequently, the meteorological ensemble is used as forcing for a hydrological model to produce an ensemble of forecasted streamflow, referred to as a hydrological ensemble prediction system (HEPS). HEPSs are increasingly being used in flood forecasting (Cloke and Pappenberger, 2009; Wetterhall et al., 2013). A HEPS adds value to a flood forecast by assessing the forecast uncertainty caused by uncertainties in one or several parts of the modeling chain.

Raw (unprocessed) ensembles are rarely reliable in a statistical sense (Buizza, 1997; Wilson et al., 2007). Reliability means that the observation behaves as if it belongs to the forecast ensemble probability distribution (Leutbecher and Palmer, 2008). To improve reliability, the ensemble forecasts can be calibrated by applying statistical techniques correcting bias and under- or over-dispersion (Hamill and Colucci, 1997; Persson, 2015). Examples of methods used to calibrate meteorological ensembles include ensemble model output statistics (EMOS) (Gneiting et al., 2005; Wilks and Hamill, 2007), Bayesian model averaging (BMA) (Raftery et al., 2005; Wilson et al., 2007), ensemble Kalman filters (Evensen, 2003; Verkade et al., 2013), non-homogenous Gaussian regression (Gneiting et al., 2005; Wilks and Hamill, 2007), quantile mapping (Bremnes, 2007), and kernel dressing (Wang and Bishop, 2005). These methods differ in their sensitivity to length of training data and ensemble size and in how the spread and bias are corrected. Preprocessing (from a hydrological perspective) refers to all techniques used to change the output from a meteorological model and includes calibration (described above) and downscaling. Downscaling implies resampling from the original forecast grid size to a grid of higher resolution, and both statistical (e.g., interpolation) and dynamical (e.g., a regional weather forecast model) techniques can be used (Schaake et al., 2010). A recent review of preprocessing methods is given in $\mathrm{Li}$ et al. (2017) and the textbook edited by Vannitsem et al. (2018).
In climates with seasonal snow cover, snowmelt during the spring season is an important flood-generating process. In these climates, temperature is a key variable to classify the precipitation phase and to estimate the snowmelt rate. The sensitivity of daily streamflow to temperature is nonlinear since streamflow depends on temperature thresholds for rain-snow partitioning and for snowmelt and freeze processes. The snowmelt and freeze processes depend on the state of the system; i.e., snow is needed to generate snowmelt. For temperatures well below $0^{\circ} \mathrm{C}$, the streamflow is not sensitive to temperature, whereas for temperatures around $0{ }^{\circ} \mathrm{C}$ relatively small changes in temperature might control if precipitation falls as rain or snow, and consequently whether streamflow is generated or not. Most Norwegian catchments experience a seasonal snow cover, but are otherwise diverse in terms of the length of the snow season and topographic complexity (Rizzi et al., 2017).

Downscaling and interpolating air temperature in complex topography are both challenging, mostly because temperature lapse rates depend on several factors, i.e., altitude, time, and place, as well as specific humidity and air temperature (Aguado and Burt, 2010; Pagès and Miró, 2010; Sheridan et al., 2010). Errors in forecasted temperature might result in a misclassification of precipitation phase and/or cause the hydrological forecasting system either to miss a flood event or provide a false alarm, caused by too-high or too-low snowmelt rates. It is therefore important to assess the relationship between temperature and streamflow forecasts. The importance of reliable temperature forecasts for streamflow forecasts is demonstrated for two Alpine catchments during a heavy precipitation event in Ceppi et al. (2013). An interesting finding in this paper is that catchment elevation distribution, and by this area above the snowline, was important for how streamflow forecasts were affected by temperature uncertainty. Verkade et al. (2013), on the other hand, found only modest effects of temperature calibration on streamflow forecast skill as an average over several years for Rhine catchments.

As far as the authors know, the isolated effect of the uncertainties in temperature forecasts has not yet been systematically investigated for a larger number of catchments in a cold climate. The large spatial and seasonal variations in snow accumulation and snowmelt processes found in cold regions with complex terrain require that both spatial and seasonal patterns in the performance of temperature and streamflow forecasts are evaluated.

The main objective of this study is to investigate the effect of temperature forecast calibration on the streamflow ensemble forecasts skill in catchments with seasonal snow cover and to identify potential improvements in the forecasting chain. In particular, we address the following research questions:

- Are there seasonal effects of temperature calibration on the temperature ensemble forecast skill? 
- Are there seasonal effects of temperature calibration on the streamflow ensemble forecast skill?

- Are there spatial patterns in the temperature and streamflow ensemble forecast skill and, if so, can these be related to catchment characteristics?

To answer these questions, we applied temperature ensemble forecasts from ECMWF combined with the preprocessing setup from MET Norway to 139 catchments in Norway. Three years of operational ECMWF forecasts from 2013 to 2015 were used to regenerate streamflow forecasts, and the skill of temperature and streamflow forecasts was systematically evaluated for these catchments. To investigate the isolated effect of the temperature ensembles on the streamflow forecasts, the observed seNorge precipitation (Tveito et al., 2005) was used instead of the precipitation ensemble forecasts to run the hydrological model. Finally, a case study is presented, demonstrating the effect of temperature calibration on a single snowmelt-induced flood event. We start by presenting the study area, data, and hydrological model (HBV) used (Sect. 2). In Sect. 3, methods used to establish the hydro-meteorological forecasting chain, the skill metrics, and evaluation strategy are presented. Section 4 contains the results, followed by a discussion in Sect. 5. Finally, in Sect. 6, the findings are summarized, conclusions are drawn, and further research questions are discussed.

\section{Study area, data, and model}

\subsection{Study area}

In Norway there are spatial variations in climate and topography, and a recent overview of past, current, and future climate is given in Hanssen-Bauer et al. (2017). The western coast has steep mountains, high annual precipitation (4000$5000 \mathrm{~mm} \mathrm{yr}^{-1}$ ), and a temperate oceanic climate. Inland areas have less precipitation, larger differences between winter and summer temperatures, and climatic zones from humid continental to subarctic and mild tundra (according to the Köppen-Geiger system; see Peel et al., 2007). The mean annual runoff follows to a large degree the spatial patterns of precipitation. The two basic flood-generating processes are snowmelt and rainfall (Vormoor et al., 2015). Most catchments in Norway have prolonged periods of subzero temperatures during winter, resulting in a seasonal snow storage, winter low flow, and increased streamflow during spring due to snowmelt. The relative importance of rainfall and snowmelt processes is decided by the duration of the snow accumulation season and the share of annual precipitation stored as snow. Across Norway two basic runoff regimes can be identified: (i) coastal regions with high flows during autumn and winter due to heavy rainfall and (ii) inland regions with high runoff during spring due to snowmelt (Vormoor et al., 2015). However, there are many possible transitions between these two basic patterns (Gottschalk et al., 1979).

The national flood-forecasting system builds on hydrological models providing streamflow forecasts in 145 catchments, covering most parts of Norway, varying in size $(\sim 3$ to $15447 \mathrm{~km}^{2}$ ) and elevation difference (103 to $2284 \mathrm{~m}$ ). The latter is calculated as the difference between the lowest and highest point on the hypsographic curve, $\Delta H=$ $\left(H_{100}-H_{0}\right)$. The flood-forecasting catchments are mostly pristine, although some do have minor (hydropower) regulations. Fourteen catchments have a glacier coverage of $5 \%$ or more. Of the 145 flood-forecasting catchments, 139 were chosen as the basis for the study (Fig. 1). The catchments were grouped into five regions based on their location: north $(\mathrm{N})$, south $(\mathrm{S})$, west $(\mathrm{W})$, middle $(\mathrm{M})$, and east (E) following Hanssen-Bauer et al. (2017) and Vormoor et al. (2016) (Fig. 1, right). These regions are defined by the boundaries of the major watersheds and reflect major hydroclimatological zones. Rainfall floods dominate in the south, west, and middle, whereas snowmelt floods dominate in the east and north. There is still a large variability in hydrological regimes within individual regions. Figure 1 includes the location of four catchments, for which results that are more detailed will be presented. Gjuvaa (E), Foennerdalsvatn (W), and Viksvatn (W) were used to visualize the challenges in temperature forecasts, and both uncalibrated and calibrated ensemble values will be presented for these three catchments. Viksvatn (W) and Foennerdalsvatn (W) are located in western Norway and are both catchments with some glaciers ( $\sim 3 \%$ and $47 \%$, respectively). Gjuvaa (E) is nonglaciered and located inland (Fig. 1, left). The Bulken (W) catchment was chosen to demonstrate the effect of temperature calibration on the streamflow forecast for a snowmeltdriven flood event.

\subsection{Observations, hydrological model, and forecasts}

\subsubsection{Interpolated precipitation and temperature observations - seNorge data}

In Norway, a network of about 400 precipitation stations and 240 temperature stations provides daily temperature and precipitation values. These in situ observations are interpolated to create a gridded $(1 \mathrm{~km} \times 1 \mathrm{~km})$ product, referred to as seNorge (available at http://www.seNorge.no/, last access: 1 February 2019, Tveito et al., 2005). In this study, we used version 1.1. For this version, gridded temperature is calculated by kriging, where both the elevation and location of temperature stations are accounted for. The observed daily precipitation is corrected for under-catch at the gauges, and triangulation is used for spatial interpolation to a $1 \mathrm{~km} \times 1 \mathrm{~km}$ grid. A constant gradient of $10 \%$ per $100 \mathrm{~m}$ beneath $1000 \mathrm{~m}$ above sea level (m a.s.l.) and $5 \%$ per $100 \mathrm{~m}$ above $1000 \mathrm{~m}$ a.s.l. is applied to account for elevation gradients in precipitation (details can be found in Tveito, 

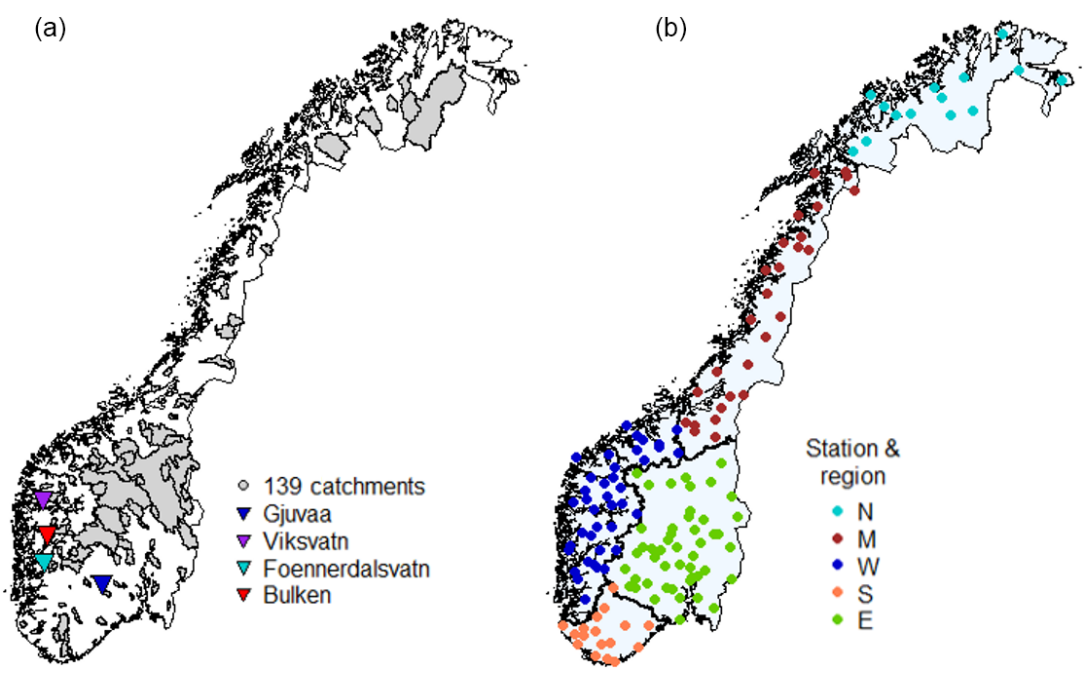

Figure 1. The maps for Norway indicate the 139 catchments used in this study. Panel (a) shows the catchment boundaries including the location of four selected catchments. Please note that many catchments are relatively small and difficult to detect. The locations of the catchment gauging stations are shown in (b). Norway was grouped into five regions (N: north, M: middle, W: west, S: south, and E: east); all regions are marked with different colors and regional boundaries.

2002; Tveito et al., 2005; and Mohr, 2008). The seNorge data are available from 1 January 1957, and in this study we used data for the period 1 March 2013 to 31 December 2015 in the forecasting mode and 1 January 1958 to 31 December 2012 to calculate the temperature and streamflow climatology (Sect. 3.2). The seNorge precipitation substitutes the precipitation forecasts in the ensemble forecasting chain, and hence the isolated effect of temperature calibration on streamflow forecasts was obtained. We hereby denote seNorge temperature and precipitation, $T_{\mathrm{o}[\text { lat,long, } t]}$ and $P_{\text {o[lat,long, } t]}$, respectively, where $t$ is an index for observation time. Latitude (lat) and longitude (long) represent the grid indexing.

\subsubsection{Hydrological model - HBV}

The HBV model (Bergström, 1976) as presented in Sælthun (1996) and Beldring (2008) constitutes the basis for this study. The vertical structure of the HBV model consists of a snow routine, a soil moisture routine, and a response function that includes a nonlinear reservoir for quick runoff and a linear reservoir for slow runoff. The model uses catchment average temperature and precipitation as input. Each catchment is divided into 10 elevation zones, each covering $10 \%$ of the total catchment area. The catchment average precipitation and temperature are elevation adjusted to each elevation zone using catchment-specific lapse rates. In this study, we used the operational model setup which has been calibrated for each catchment individually. PEST, a software for parameter estimation and uncertainty analysis (Doherty, 2015), was used to optimize the HBV parameters, with the Nash-Sutcliffe efficiency (Nash and Sutcliffe, 1970) and volume bias as calibration metrics. The calibration period,
1996-2012, gives a mean Nash-Sutcliffe efficiency value of 0.77 , with zero volume bias for the 139 catchments. The validation period, 1980-1995, shows a mean Nash-Sutcliffe efficiency value of 0.73 , with a mean volume bias of $5 \%$ (Ruan Gusong, personal communication, 15 June 2016). We used one optimal parameter set for each catchment and therefore ignored uncertainty arising from parameter estimation and the hydrological model.

\subsubsection{Reference streamflow}

Reference streamflow, $Q_{\mathrm{o}[c, t]}$, where $c$ is an index for catchment, was derived using seNorge precipitation and temperature, aggregated to the catchment scale, as forcing to the HBV model (Fig. 2; see "Reference mode" in the green frame). In order to isolate the effect of temperature calibration on forecasted streamflow and avoid effects of hydrological model deficiencies, reference streamflow was used as a benchmark when the streamflow forecasts were evaluated. Similarly, operational flood warning levels (here demonstrated for the case study basin, Bulken) are based on return periods from reference streamflow.

\subsubsection{Temperature ensemble forecasts}

We used the ECMWF temperature forecast ensemble (ENS) for the period 1 March 2013 to 31 December 2015 from an original grid resolution of $0.25^{\circ}$ (i.e., model cycles/versions 38r1/2, 40r1, and 41r1; ECMWF, 2018b). This period covers model cycles/versions for which temperature grid calibration parameters are trained (40r1 and 41r1; see Sect. 3.1.2) plus spring 2013 (cycle 38r1/2) in order to include one more snowmelt season. In short, 50 ensemble members of ENS 


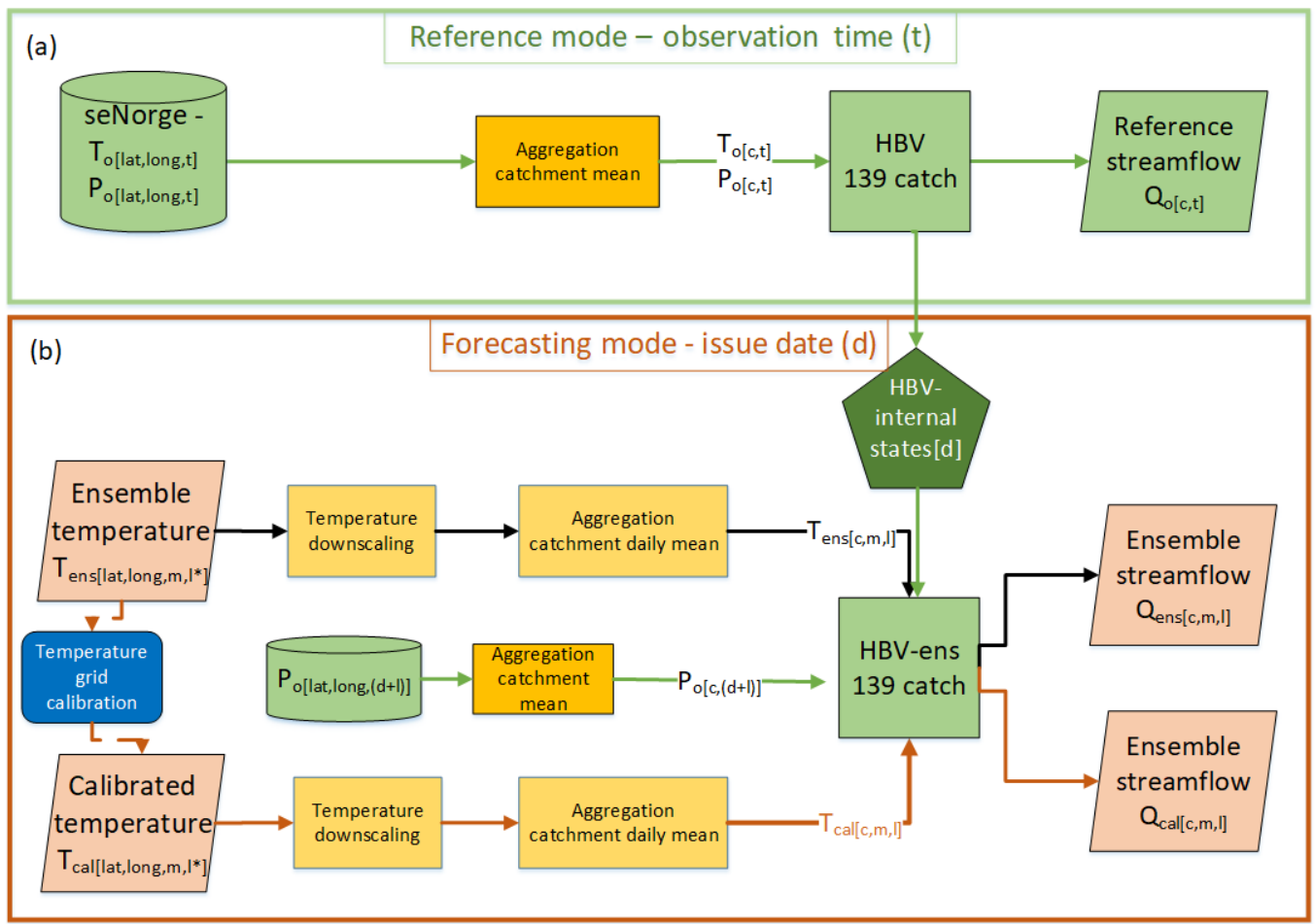

Figure 2. Conceptual diagram of the ensemble forecasting chain. Panel (a) shows the reference mode that is the calculation of reference streamflow using the HBV model with catchment aggregated daily mean values of seNorge temperature $\left(T_{\mathrm{o}}\right)$ and precipitation $\left(P_{\mathrm{O}}\right)$. In the forecasting mode (b), ECMWF temperature ensembles are downscaled to $1 \mathrm{~km} \times 1 \mathrm{~km}$ prior to catchment aggregation. Calibrated temperature $\left(T_{\text {cal }}\right)$ is estimated from $T_{\text {ens }}$, applying a grid calibration at $5 \mathrm{~km} \times 5 \mathrm{~km}$ resolution. Daily average forecast values $\left(T_{\text {ens }}\right.$ or $\left.T_{\text {cal }}\right)$ and observed precipitation $\left(P_{\mathrm{o}}\right)$ are used to force the hydrological model at the forecasting issue date $(d)$, with internal states from the reference mode.

are generated by adding small perturbations to the forecast initial conditions and model physics schemes, subsequently running the model with different perturbed conditions. The ensemble represents the temperature forecast uncertainty. A more detailed description of the ECMWF ENS system is provided in, for example, Buizza et al. $(1999,2005)$ and Persson (2015). For each issue date $d, 51$ ensemble members $T_{\mathrm{ens}\left[\text { lat,long, } m, l^{*}\right]}$ are provided for a lead time of up to $246 \mathrm{~h}$, where $m$ is the ensemble member and $l^{*}$ the lead time in $6 \mathrm{~h}$ intervals. In this study, we used the forecasts issued at 00:00 UTC and aggregated daily values for the meteorological $24 \mathrm{~h}$ period defined as 06:00-06:00 to provide forecasts for lead times of up to 9 days. The observational time $t$ for a forecast is $d+l^{*}$.

\section{Methods}

\subsection{Ensemble forecasting chain}

Figure 2 shows the forecasting modeling chain designed for this study. The green frame presents the observational reference mode that determines the internal states for the forecasting issue date, $d$, in the red frame. This reference mode was also used to estimate reference streamflow $Q_{\mathrm{o}[c, t]}$ (see Sect. 2.2.3). The seNorge temperature and precipitation ( $T_{\mathrm{O}[c, t]}$ and $\left.P_{\mathrm{o}[c, t]}\right)$, aggregated to each catchment $c$, were used to force the hydrological model in the observational reference mode. The red frame illustrates the forecasting mode, including the post-processing of temperature forecasts. The hydrological ensemble forecasts were estimated using downscaled raw temperature ensemble forecasts $\left(T_{\mathrm{ens}[c, m, l]}\right.$; see Sect. 3.1.1) or downscaled and calibrated temperature ensemble forecasts $\left(T_{\mathrm{cal}[c, m, l]}\right.$; see Sect. 3.1.2) and observed precipitation $\left(P_{\mathrm{O}[c, d+1]}\right)$ as forcing, where $m$ is the ensemble member and $l$ is lead time in days. All temperature forecasts were aggregated to daily time steps since the operational HBV model runs on a daily time step and the seNorge data used as a reference provide only daily values. In the forecasting mode, each temperature ensemble member was used as input and run as a separate deterministic forecast. All hydrological forecasts were estimated for all nine lead times. Note that for each issue date $d$, the same internal states of the HBV model were used for all ensemble member runs. Thus two sets of streamflow ensemble forecasts $\left(Q_{\mathrm{ens}[c, m, l]}\right.$ and $\left.Q_{\mathrm{cal}}[c, m, l]\right)$ that differ only by the applied temperature calibration were derived. The following subsections provide 
details on the approach used for downscaling and calibration of the ensemble temperature forecasts (ENS).

\subsubsection{Temperature forecast downscaling}

In this paper the term downscaling refers to the interpolation of temperature from a low-resolution grid to a highresolution grid where vertical temperature gradients are accounted for. The ECMWF grid temperature, which represent the average temperature for the grid cell, was interpolated from a horizontal resolution of $0.25^{\circ}(\sim 30 \mathrm{~km})$ to the $1 \mathrm{~km} \times 1 \mathrm{~km}$ seNorge grid, using the nearest-neighbor method and aggregated to daily values to match the spatial and temporal resolution of the seNorge data. Due to elevation differences between the ECMWF and seNorge grid elevations, we corrected the ensemble temperature at the $1 \mathrm{~km} \times 1 \mathrm{~km}$ scale by applying a standard atmospheric lapse rate of $-0.65^{\circ} \mathrm{C} 100 \mathrm{~m}^{-1}$. Finally, the downscaled temperature ensemble was aggregated to daily values and averaged over the catchment areas to provide $T_{\mathrm{ens}[c, m, l]}$ for a given lead time and ensemble member.

\subsubsection{Temperature grid calibration}

The grid temperature is calibrated using quantile mapping (Seierstad et al., 2016; Bremnes, 2007) to remove biases by moving the ENS forecast climatology closer to the observed climatology. MET Norway provided temperature grid calibration parameters used in this study. This grid calibration was used in the operational post-processing chain for meteorological forecasts including the forecasts published on http: //yr.no (last access: 1 February 2019). MET Norway uses HIRLAM (High Resolution Limited Area Model, Bengtsson et al., 2017) temperature forecasts (on a $4 \mathrm{~km} \times 4 \mathrm{~km}$ grid) to provide a reference for parameter estimation (calibration). HIRLAM is suitable as a reference since it provides a continuous field covering all of Norway at a sub-daily time step. In addition, HIRLAM gives higher skill and is less biased than ENS (Engdahl and Homleid, 2015). To establish the calibration parameters, MET Norway used both ENS reforecasts (Owens and Hewson, 2018) and HIRLAM data from July 2006 to December 2011 interpolated to a $5 \mathrm{~km} \times 5 \mathrm{~km}$ grid. The ENS reforecast is a five-member ensemble generated from the same model cycle (40r1 and 41r1) as ENS. For each grid cell, monthly unique quantile transformation coefficients are determined by using data from a 3-month window centered on the target month; e.g., the May analysis consists of April, May, and June (Ivar Seierstad, personal communication, 10 November 2017). The same coefficients, based on mapping the first $24 \mathrm{~h}$, were applied to all lead times and members. For forecasts outside the observation range, a $1: 1$ extrapolation was used. That is, if a forecast is $2{ }^{\circ} \mathrm{C}$ higher than the highest mapped forecasted temperature, then the calibrated forecast is $2{ }^{\circ} \mathrm{C}$ higher than the highest mapped reference temperature.
For this study, we applied the calibration coefficients provided by MET Norway to the temperature forecasts for the period 2013-2015. Accordingly, ENS was interpolated to the $5 \mathrm{~km} \times 5 \mathrm{~km}$ grid for which the quantile mapping coefficients were used to obtain the calibrated temperature ensembles $\left(T_{\text {cal }}\right)$. Subsequently, the calibrated ensembles on the $5 \mathrm{~km} \times 5 \mathrm{~km}$ grid were downscaled to the $1 \mathrm{~km} \times 1 \mathrm{~km}$ grid following the same procedure as for the uncalibrated temperature ensemble ( $T_{\text {ens }}$, Sect. 3.1.1). Finally, the calibrated temperature ensemble was aggregated to daily values and averaged over the catchment areas to provide $T_{\mathrm{cal}}[c, m, l]$.

\subsection{Validation scores and evaluation strategy}

The evaluation focused on the performance of the temperature forecast ensembles and the effect of both uncalibrated and calibrated temperature forecasts on the performance of the streamflow ensembles. A well-performing ensemble forecast should be reliable and sharp, where reliability has the first priority (Gneiting et al., 2007). A forecast is considered reliable if it is statistically consistent with the observed uncertainty; i.e., $90 \%$ of the observations should verify within the $90 \%$ forecast interval. Rank histograms are often used for visual evaluation of reliability and show the frequencies of observations amongst ranked ensemble members. For reliable ensemble forecasts, the rank histogram will be uniform (horizontal). A bias in the ensemble forecast is recognized as a slope in the rank histogram, where a negative slope indicates too-warm temperature forecasts and a positive slope too-cold forecasts. A U shape indicates that the ensemble forecast is under-dispersed, whereas a convex shape indicates over-dispersion (Hamill, 2001). In order to quantify the reliability, a decomposition of the chi-squared test statistics for the rank histogram was used to describe the rank-histograms slope (bias) and convexity (dispersion) (Jolliffe and Primo, 2008). Both rank-histogram slope and convexity are negatively oriented; i.e., lower values are better, with an optimal value of zero for unbiased and uniformly distributed data. The sharpness of a reliable forecast is described by the spread between the ensemble members, where a sharp forecast has a small spread and is the most useful (Hamill, 2007). In this study, the temperature sharpness was assessed by first estimating the range between the 5 th and the 95 th percentile of the ordered ensemble forecasts for all issue dates, lead times, and catchments. For streamflow, we estimated a relative sharpness by dividing the 5 th to 95 th percentile range by the ensemble mean. Thereafter, sharpness was determined for each catchment and lead time as the average range of all issue dates. The continuous rank probability score (CRPS) is a summary of reliability, sharpness, and uncertainty (Hersbach, 2000). CRPS (denoted as $S_{\mathrm{CRP}}$ in Eq. 1) measures the distance between the observation $x_{a}$ and the ensemble forecast, where the latter is expressed by the cumulative density function $F_{x}(x)$ : 

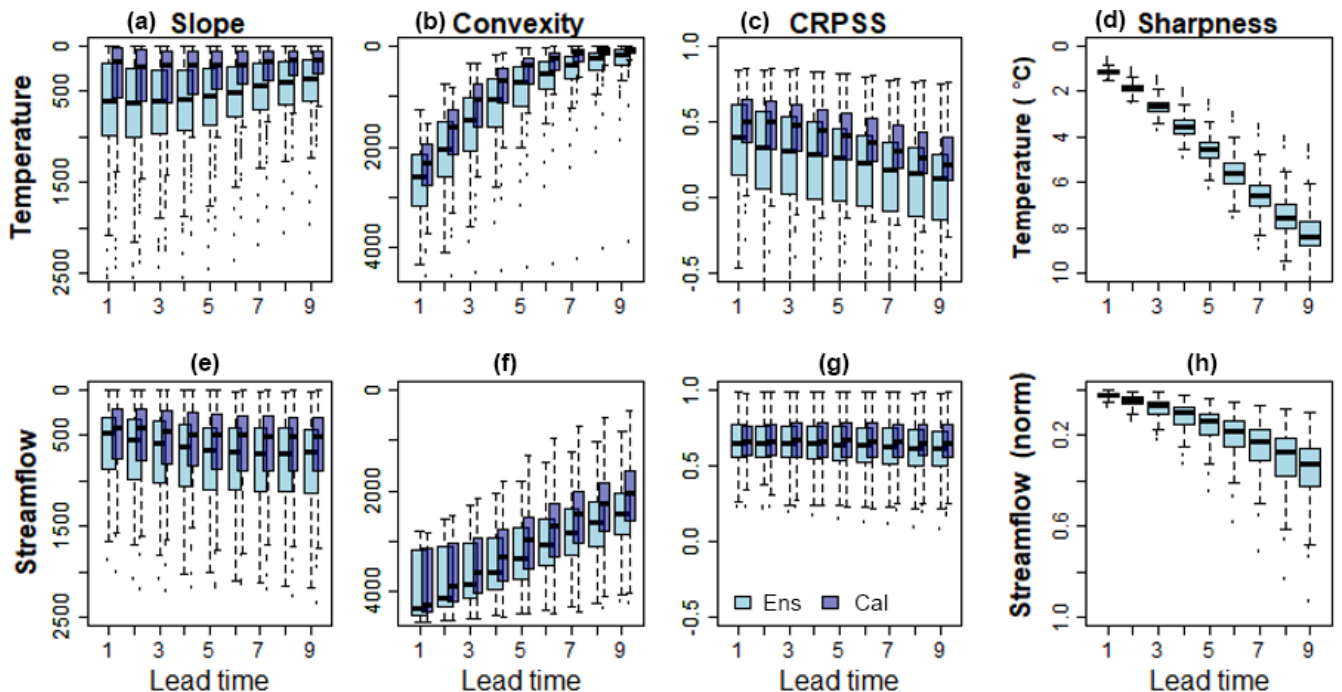

Figure 3. Summary of temperature and streamflow scores for all lead times. Each box represents the 139 catchments values averaged over all issue dates. Rank-histogram test decomposition for slope and convexity is shown in (a), (e), (b), and (f), respectively, and CRPSS in (c) and (g). Panels (d) and (h) show sharpness for the uncalibrated forecasts. Temperature is shown in panels (a)-(d) and streamflow in (e)-(h). Results are based on the full dataset and are shown for both uncalibrated (light blue) and calibrated (blue) ensembles at lead times of 1 to 9 days. For slope and convexity, 0 is the optimal value, and the scales are reversed so that the optimal value is on the top, corresponding to the CRPSS optimal value at 1.0.

$S_{\mathrm{CRP}}\left(F_{x}, x_{a}\right)=\int_{-\infty}^{\infty}\left[F_{x}(x)-H\left(x-x_{a}\right)\right]^{2} \mathrm{~d} x$,

where $H$ is the Heaviside function that is zero when the argument is less than zero, and one otherwise (Hersbach, 2000). $\overline{\text { CRPS }}$ was calculated as the average CRPS $\left(S_{\mathrm{CRP}}\right)$ over the study period (1 March 2013 to 31 January 2015). $\overline{\text { CRPS }}$ is similar to the mean absolute error for deterministic forecasts. The temperature $\overline{\mathrm{CRPS}}$ was computed using the seNorge temperature $T_{\mathrm{o}}$ as observations, whereas streamflow $\overline{\text { CRPS used }} Q_{\mathrm{o}[c, t]}$ as observations. This evaluation approach allowed us to evaluate the isolated effect of the uncertainties in the temperature forecasts since we can then, to a large degree, ignore uncertainties in the HBV model itself.

Skill scores are convenient for comparison between forecast variables (e.g., temperature versus streamflow) and catchments since these scores are dimensionless. To calculate the continuous ranked probability skill score (CRPSS denoted as $S_{\text {CRPS }}$ in Eq. 2), a benchmark is needed. The benchmark is a reference forecast which a skillful forecast should outperform. For both temperature and streamflow, ensembles representing daily climatology were used as benchmarks. Daily seNorge temperatures $\left(T_{\mathrm{O}[c, t]}\right)$ from 1958 to 2012 (i.e., 55 years) were used to create a climatological temperature ensemble of 55 members for each day of the year. Similarly, a daily streamflow climatology was established from reference streamflow $\left(Q_{\mathrm{o}[c, t]}\right)$ calculated by the HBV model, forced with the 55 years of temperature and precipitation $\left(T_{\mathrm{O}[c, t]}\right.$ and $\left.P_{\mathrm{o}[c, t]}\right)$ from the seNorge data.

CRPSS ( $S_{\text {CRPS }}$ ) was calculated for each catchment according to Eq. (2) (Hersbach, 2000). CRPSS ( $S_{\text {CRPS }}$ ) was calculated for each catchment according to Eq. (2) (Hersbach, 2000 ), where $\bar{S}_{\mathrm{B}_{-} \mathrm{CRP}}$ is the benchmark score and $\bar{S}_{\mathrm{F}_{-} \mathrm{CRP}}$ is the forecast score (denoted as $\overline{\mathrm{CRPS}}$ in the text, calculated for the benchmark and forecast, respectively).

$S_{\mathrm{CRPS}}=\frac{\bar{S}_{\mathrm{B} \_\mathrm{CRP}}-\bar{S}_{\mathrm{F} \_\mathrm{CRP}}}{\bar{S}_{\mathrm{B} \_\mathrm{CRP}}}$

CRPSS varies from $-\infty$ to 1 , where 1 is a perfect score. Negative values mean that the forecast performs worse than climatology, and CRPSS equal to 0 implies that it performs similarly to the benchmark (climatology in this case). The seasonal skill score was calculated by averaging the daily CRPS only for the months belonging to the target season. The effect of the grid calibration on the temperature and streamflow forecast skill was evaluated by comparing the validation scores using both the uncalibrated $\left(T_{\text {ens }}\right)$ and the calibrated $\left(T_{\text {cal }}\right)$ ensembles to generate the streamflow ensembles. For readability, the abbreviations $S_{\mathrm{CRP}}$ and $S_{\mathrm{CRPS}}$ used in the equation will be substituted with CRPS and CRPSS in the text hereafter.

Spatial patterns in the forecast performance for all 139 catchments, i.e., CRPSS and differences in CRPSS between calibrated and uncalibrated temperature, were mapped for Norway. Further, box plots for the five regions (see Fig. 1) were drawn to reveal potential regional patterns. Finally, we used linear regression to identify relationships between 
catchment characteristics (elevation difference and catchment area) and the skill score ( $T_{\text {cal }}$ and $Q_{\text {cal }}$ CRPSS). The linear regression analysis was done for combinations of seasons and regions. Seasonal variations in skill score were assessed by calculating CRPSS for the two seasons, spring (April to June) and autumn (October to December). This definition of seasons is used to better capture a snowmelt season, which for most Norwegian catchments is in the period April to June. For this paper, we chose to focus on the results for autumn and spring. Summer (July to September) was excluded due to the relatively small changes in CRPSS explained by the following: (i) the skill of uncalibrated temperature forecasts is higher and the potential for improvement is lower; and (ii) there is less or no snow in summer, resulting in a reduced streamflow sensitivity to temperature. Winter (January to March) was excluded since it performs similarly to autumn.

Finally, the effect of temperature calibration on the flood warning level is illustrated for a snowmelt-induced flood event in the Bulken catchment. In the operational flood warning system at NVE, the predefined flood thresholds are catchment specific and calculated return periods are based on reference streamflow, which is also the approach used herein.

\section{Results}

Temperature and streamflow forecasts were estimated for 139 catchments, 1036 issue dates, and nine lead times. Figure 3 presents a summary of the validation scores, CRPSS, and the rank-histogram decomposition, in addition to sharpness, for all lead times. Each box plot shows the variations in the validation scores between the catchments. The rankhistogram slope and convexity describe bias and dispersion in the forecasts, respectively; both can be considered a measure for the reliability. As shown in Fig. 3, temperature slope and convexity improve with increasing lead time, whereas CRPSS and sharpness get poorer. For streamflow, slope and sharpness get poorer and convexity improves, whereas CRPSS shows small changes with lead time. To reduce the amount of presented results, the remaining part of this paper focuses on CRPSS for a lead time of 5 days. CRPSS was the chosen validation score since it contains information on reliability, uncertainty, and sharpness and enables a comparison between catchments. A lead time of 5 days was chosen since reliability (convexity and slope) has improved and some sharpness is maintained; i.e., a too-large ensemble spread will increase the reliability but the forecast value will be reduced.

\subsection{Temperature forecasts}

Time series of seNorge daily temperature $T_{\mathrm{o}}$, the range of raw (uncalibrated) temperature ensembles $T_{\text {ens }}$ (left panels), and scatter plots of ensemble mean for both raw $T_{\text {ens }}$ and calibrated $T_{\text {cal }}$ versus $T_{\mathrm{o}}$ (right panels) are shown for three selected catchments in Fig. 4. For Gjuvaa (E), a high-altitude catchment (Fig. 1), $T_{\mathrm{O}}$ lies within the range of $T_{\mathrm{ens}}$ for most days, and temperature forecast $T_{\text {cal }}$ was improved by the temperature calibration. The well-performing raw temperature forecasts for this catchment are representative for most catchments in eastern Norway. Representing western Norway, raw $T_{\text {ens }}$ in Viksvatn (W) has a seasonal cold bias that is reduced by the temperature calibration. The cold bias is typical for several catchments in the coastal west, middle, and north regions. Another western catchment, Foennerdalsvatn (W), has a similar cold bias in $T_{\text {ens }}$ to Viksvatn (W), but for Foennerdalsvatn the bias is notable for all seasons and even increases for $T_{\text {cal }}$ (Fig. 4).

\subsection{Skill - relations to season, spatial location, and catchment characteristics}

Scatter plots of the difference between CRPSS for calibrated and uncalibrated forecasts for the temperature ( $T_{\text {cal }}$ and $\left.T_{\text {ens }}\right)$ and streamflow ( $Q_{\text {cal }}$ and $\left.Q_{\text {ens }}\right)$ ensembles are shown in Fig. 5. Each dot represents a catchment and the color indicates the region. The two panels in Fig. 5 show how the change in temperature CRPSS affects the change in streamflow CRPSS for spring and autumn. For spring, the relationship is close to the $1: 1$ line, whereas for autumn streamflow is less sensitive to the temperature calibration.

Catchment CRPSSs for spring and autumn were sorted according to increasing CRPSS for $T_{\text {ens }}$ and $Q_{\text {ens }}$ in Fig. 6. The figure reveals that $T_{\text {ens }}$ is more skillful in spring than in autumn when $T_{\text {ens }}$ has no skill (i.e., CRPSS $<0$ ) for about half of the catchments (i.e., they perform poorer than the climatology). In spring, $97 \%$ of catchments have skillful temperature forecasts. Temperature calibration improved the temperature skill for most catchments in autumn, whereas for many catchments in spring, the skill worsened. For streamflow, $Q_{\text {ens }}$, there are only small differences in CRPSS between spring and autumn (Fig. 6 right panels). Calibration of temperature improved the skill for streamflow, $Q_{\text {cal }}$, in autumn. Whereas for spring, the streamflow forecast skill followed the temperature skill change and is both reduced and improved.

CRPSS for uncalibrated temperature and streamflow forecasts and the change in CRPSS, calculated as the difference in CRPSS between calibrated and uncalibrated forecasts, were mapped for all catchments. Figures 7 and 8 show the CRPSS values for spring and autumn, respectively. The figures include box plots showing the variations in skill within each region, for both calibrated and uncalibrated forecasts. Neither $T_{\text {ens }}$ nor $Q_{\text {ens }}$ skill show any clear spatial pattern in spring (Fig. 7 left panel). For autumn, however, $T_{\text {ens }}$ has the lowest skill for the coastal catchments (Fig. 8 left panel). A coastal low CRPSS in autumn is also seen for $Q_{\text {ens }}$, even though less distinct compared to $T_{\text {ens. }}$. Both temperature and streamflow CRPSS were improved by calibration for the coastal regions (Fig. 8 right panel). 

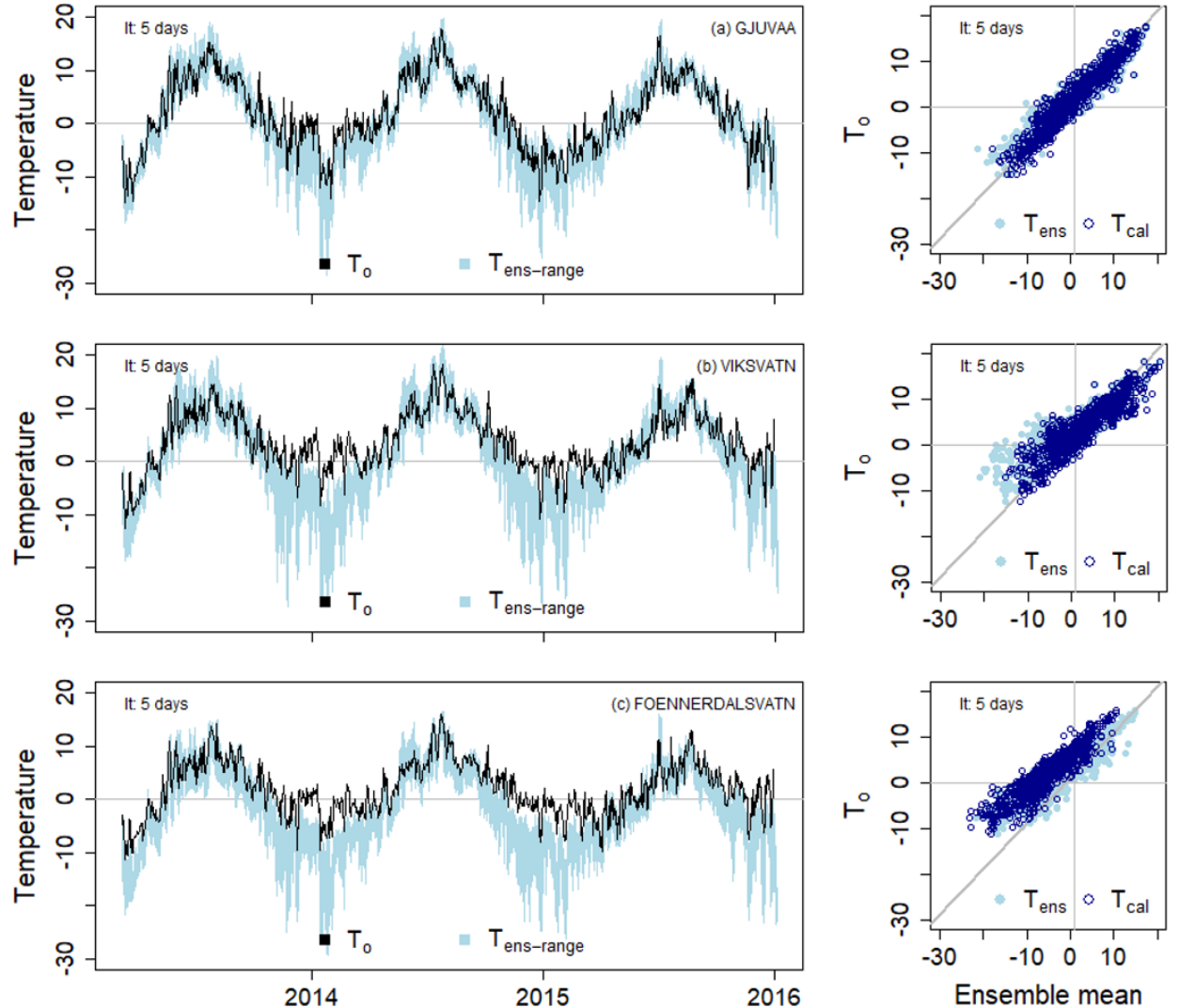

Figure 4. Time series of temperature for Gjuvaa (a), Viksvatn (b), and Foennerdalsvatn (c) showing the range of uncalibrated tempera-

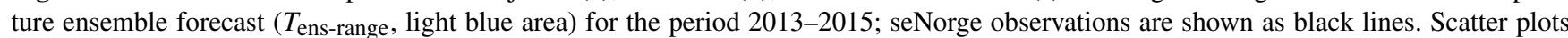
show ensemble mean temperature for both calibrated $\left(T_{\text {cal }}\right.$, blue) and uncalibrated $\left(T_{\text {ens }}\right.$, light blue) temperature plotted against seNorge temperature $\left(T_{\mathrm{O}}\right)$. Lead time (lt) is 5 days.
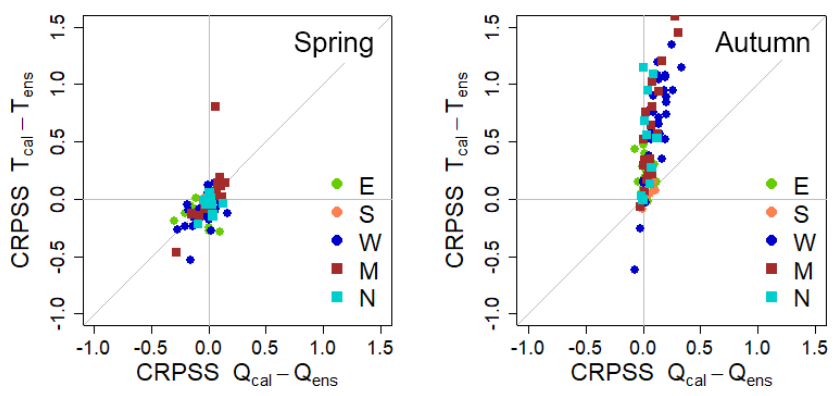

Figure 5. Difference in CRPSS for uncalibrated and calibrated temperature for spring and autumn. The difference in temperature skill is plotted on the $y$ axis and the difference in streamflow skill on the $x$ axis. The grey diagonal represent the $1: 1$ line. Catchment values are color indexed by region. All plots are presented for a lead time of 5 days.

Table 1 summarizes the result of the linear regression analysis between catchment characteristics (i.e., catchment area and elevation difference) and skill. By indicating the significance and sign of the relationships, significant relationships were found for 12 out of 40 regression equations $(5 \%$ sig- nificance level). Elevation difference is negatively correlated to streamflow CRPSS for the east and middle regions. The east region also has a negative correlation between streamflow CRPSS and catchment area as opposed to the other regions that have a positive correlation. The correlation does not change sign between the seasons for any of the regions. Calibrated temperature and streamflow CRPSS plotted as a function of catchment area are presented for the east and south in Fig. 9.

\subsection{Snowmelt flood 2013}

Forecasts and observations for a snowmelt-driven flood are presented in Fig. 10 for Bulken (W), located in western Norway. The figure shows forecasted streamflow for lead times of 2, 5, and 9 days for the target dates 16-26 May 2013. Note that for the lead times of 2,5 , and 9 days, the forecasts for 18 May are issued on 16, 13, and 9 May, respectively. The horizontal grey dotted lines represent the mean annual, the 5year, and the 50-year floods (i.e., the operational flood warning levels) in this catchment. Figure 10 reveals how temperature calibration increases the streamflow for Bulken, leading to a change in warning level for all lead times. In addition we 

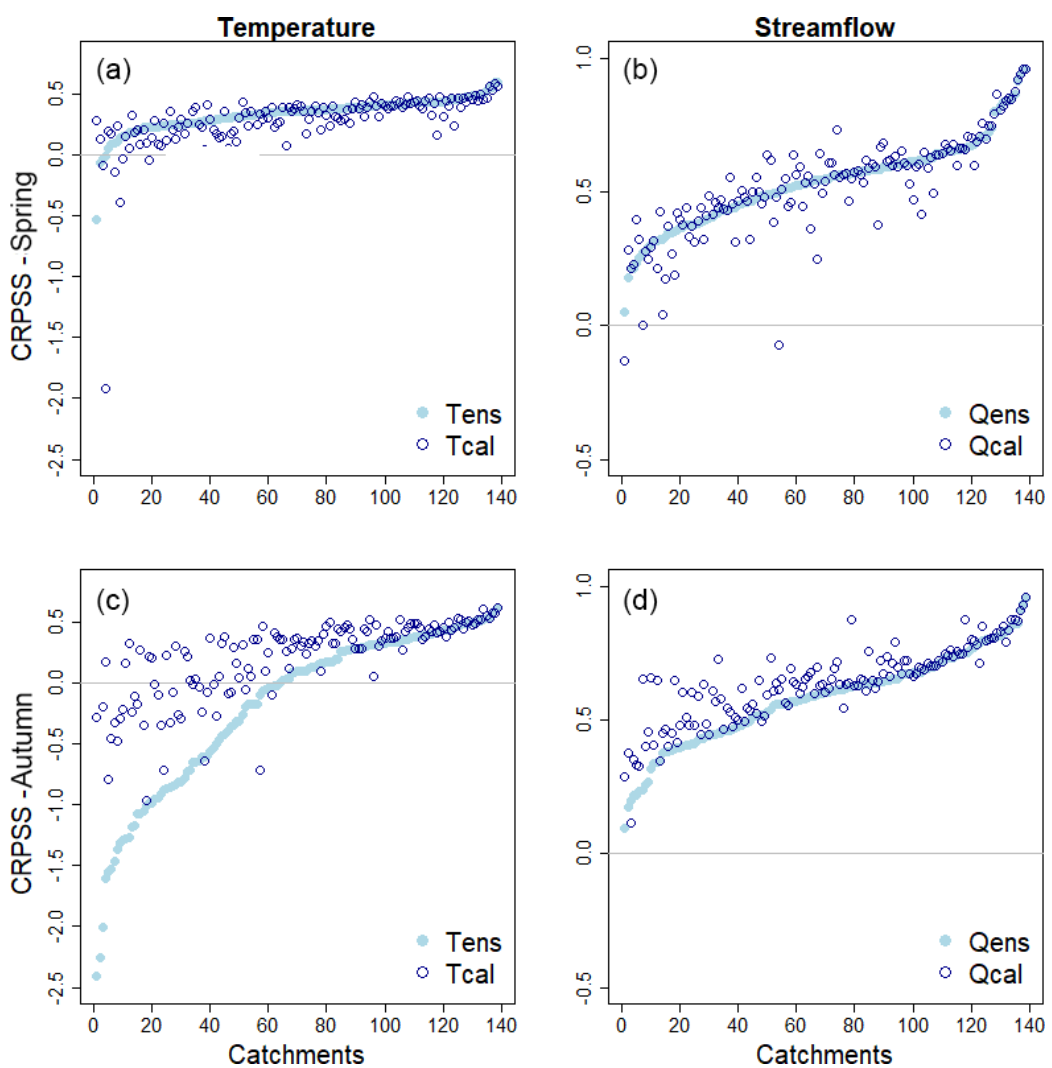

Figure 6. Temperature ( $T_{\text {ens }}$ and $\left.T_{\text {cal }}, \mathbf{a}, \mathbf{c}\right)$ and streamflow $\left(Q_{\text {ens }}\right.$ and $\left.Q_{\text {cal }}, \mathbf{b}, \mathbf{d}\right)$ CRPSS for SPRING (a, b) and AUTUMN (c, d). The catchments are ordered by increasing CRPSS for $T_{\text {ens }}$ and $Q_{\text {ens }}$ (light blue dots); the catchment calibrated values $\left(T_{\text {cal }}\right.$ and $\left.Q_{\text {cal }}\right)$ are plotted as blue circles. All results are presented for a lead time of 5 days.

Table 1. Summary of significant correlations between CRPSS for calibrated temperature $\left(T_{\text {cal }}\right)$ and streamflow $\left(Q_{\text {cal }}\right)$ ensembles and catchment characteristics, i.e., area and elevation difference $(\Delta H)$, for the five regions. " $\checkmark$ " indicates a significant positive relationship, " $x$ " a significant negative relationship, and "ns" a non-significant relationship. Results are for a lead time of 5 days.

\begin{tabular}{llcc|cc}
\hline & & $T_{\text {cal }}$ & $Q_{\text {cal }}$ & $T_{\text {cal }}$ & $Q_{\text {cal }}$ \\
\cline { 3 - 6 } & & \multicolumn{2}{c|}{ SPRING } & AUTUMN \\
\hline \multirow{2}{*}{ Area $\left(\mathrm{km}^{2}\right)$} & East & ns & $\times$ & $\mathrm{ns}$ & $\times$ \\
& South & $\checkmark$ & $\checkmark$ & $\mathrm{ns}$ & $\checkmark$ \\
& West & $\checkmark$ & $\mathrm{ns}$ & $\mathrm{ns}$ & $\mathrm{ns}$ \\
& Middle & $\checkmark$ & $\mathrm{ns}$ & $\checkmark$ & $\mathrm{ns}$ \\
& North & $\mathrm{ns}$ & $\mathrm{ns}$ & $\checkmark$ & $\mathrm{ns}$ \\
\hline$\Delta H(\mathrm{~m})$ & East & $\mathrm{ns}$ & $\times$ & $\mathrm{ns}$ & $\times$ \\
& South & $\mathrm{ns}$ & $\mathrm{ns}$ & $\mathrm{ns}$ & $\mathrm{ns}$ \\
& West & $\mathrm{ns}$ & $\mathrm{ns}$ & $\mathrm{ns}$ & $\mathrm{ns}$ \\
& Middle & $\mathrm{ns}$ & $\mathrm{ns}$ & $\mathrm{ns}$ & $\times$ \\
& North & $\mathrm{ns}$ & $\mathrm{ns}$ & $\mathrm{ns}$ & $\mathrm{ns}$ \\
\hline
\end{tabular}

see how the ensemble spread increases with lead time (from lower to upper panel), from a narrow range around the ensemble mean for the lead time of 2 days to a very wide range for a lead time of 9 days.

\section{Discussion}

Box plots of validation scores for all catchments and lead times in Fig. 3 show that, on average, both raw $T_{\text {ens }}$ and calibrated $T_{\text {cal }}$ temperature ensembles were more skillful with a higher CRPSS, for shorter as compared to longer lead times, and that $T_{\text {cal }}$ was more skillful than $T_{\text {ens. }}$. Even though both bias and dispersion (i.e., reliability) as measured by rankhistogram slope and convexity improved with longer lead times, the reduced sharpness and increased uncertainty resulted in a reduced skill (CRPSS). For streamflow, the bias increased with longer lead times, while dispersion improved. Further, $Q_{\text {cal }}$ was slightly more skillful than $Q_{\text {ens. }}$ Overall, the grid calibration of temperature had a positive effect on both temperature and streamflow for most validation scores and lead times. The calibration procedure applied in this study involves many interpolations and downscaling steps that increase the uncertainty in temperature forecasts. We be- 

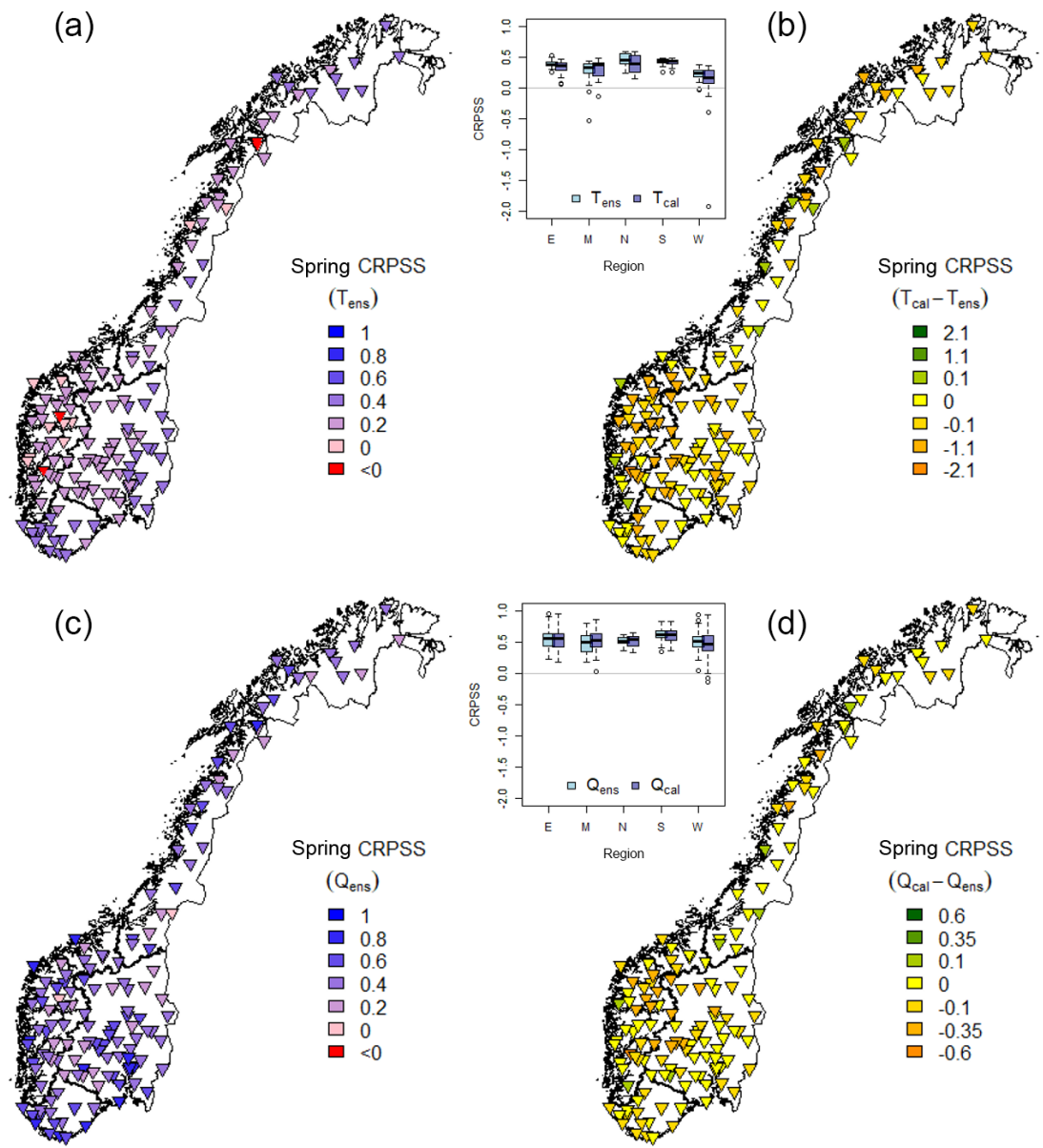

Figure 7. Spring CRPSS for uncalibrated forecasts (a, c) and CRPSS difference between calibrated and uncalibrated forecasts (b, d) for temperature $(\mathbf{a}, \mathbf{b})$ and streamflow $(\mathbf{c}, \mathbf{d})$. A darker blue color $(\mathbf{a}, \mathbf{c})$ indicates an optimal performance (maximum CRPSS $=1.0)$, pink a CRPSS of zero, and red a negative value. A green color $(\mathbf{b}, \mathbf{d})$ indicates a positive effect of temperature calibration on the skill, yellow means no effect, and an orange color indicates a negative effect. The box plots show temperature and streamflow CRPSSs grouped by region (Fig. 1). All results are presented for a lead time of 5 days.

lieve that a catchment-specific temperature calibration, tailored to the needs of hydrological forecasting, would solve this challenge.

\subsection{Effect of temperature calibration for the temperature forecast skill}

The skill for both raw (uncalibrated) $T_{\text {ens }}$ and calibrated $T_{\text {cal }}$ temperature ensembles varies with season (Figs. 5-8). The relatively small temperature skill improvements in spring and large skill improvements in autumn can be explained by the skill of the raw ensembles $T_{\text {ens. }}$. The low skill for $T_{\text {ens }}$ in autumn and winter is caused by a cold bias and lays the foundation for the large improvements seen for $T_{\text {cal }}$. The seasonal differences in skill and response to calibration show the importance of using seasonal calibration parameters. It is also apparent that the applied methods do not perform optimally for all seasons. For spring, the results show that several catchments have a reduction in the forecast skill after calibration. By inspecting the forecasts in detail, we found a too-extensive correction of temperature for some days and catchments. Quantile mapping, as most statistical techniques, is sensitive to forecasts outside the range of calibration values and periods (Lafon et al., 2013), which can be an explanation for too high a correction in the highest $T_{\text {ens }}$ quantile. The use of forecasts from different model cycles might affect the consistency in the forecasts. Moreover, the calibration parameters are sensitive to the representativeness of the calibration period.

The most pronounced spatial pattern is the low autumn CRPSS for uncalibrated ensembles $T_{\text {ens }}$ in the coastal areas. This is seen in the box plots for the west, middle, and north regions (Fig. 8) and in the plots of the western catchments Viksvatn and Foennerdalsvatn during winter months (Fig. 4). This cold bias is documented for the Norwegian coastal areas in the cold seasons by Seierstad et al. (2016) and is mainly caused by the radiation calculations in the ECMWF model 

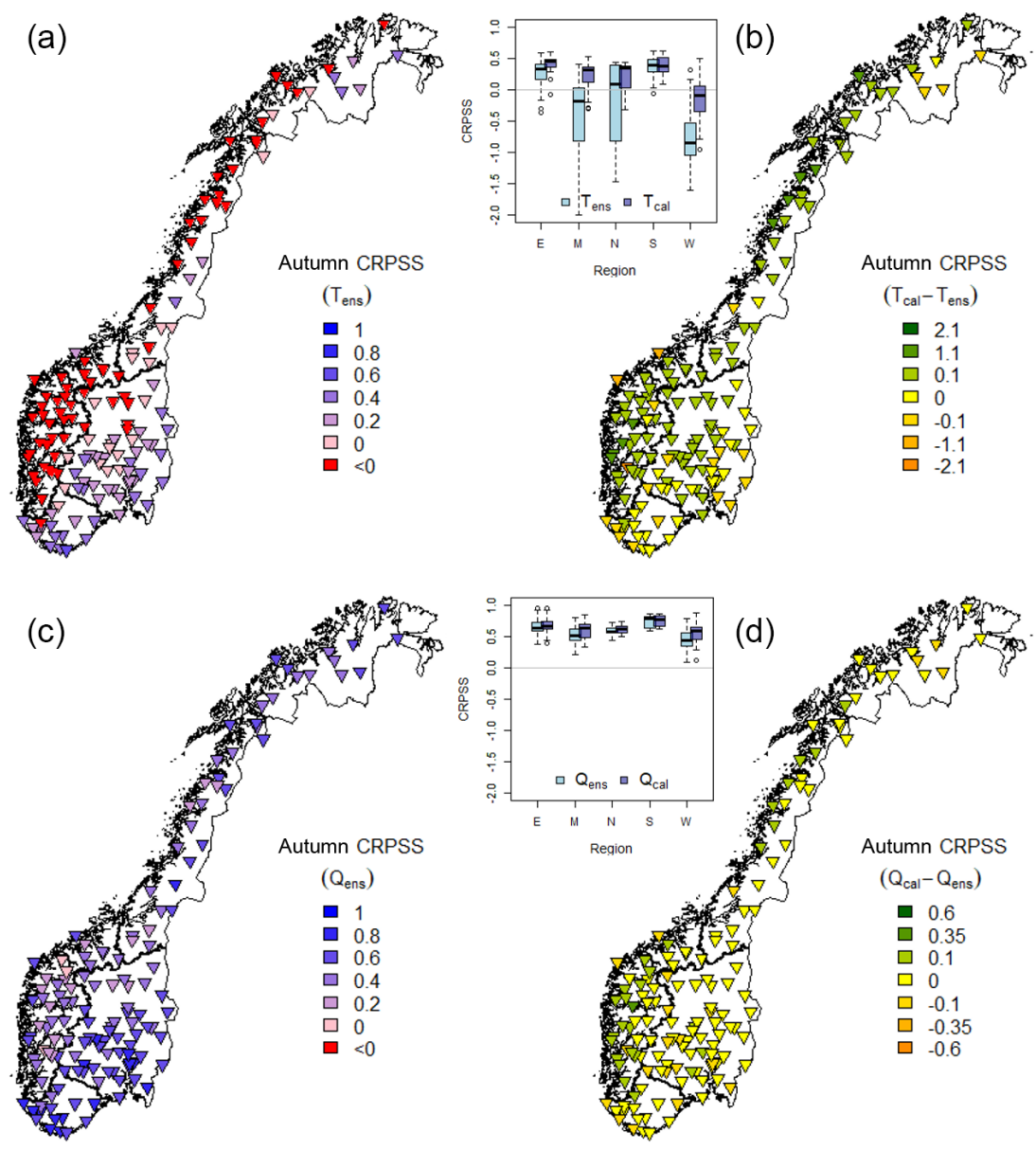

Figure 8. Autumn CRPSSs for uncalibrated forecasts are presented in panels (a) and (c), where the darker blue color indicates an optimal performance (maximum CRPSS $=1.0$ ), pink color represents a CRPSS of zero, and red a negative value. The differences in CRPSS between calibrated and uncalibrated forecasts are presented in panels (b) and (d), where the green color indicates a positive effect of temperature calibration on the skill, yellow zero, and orange color indicates a negative effect. Temperature CRPSS is presented in (a) and (b) and streamflow CRPSS in (c) and (d). The box plots of both calibrated and uncalibrated temperature and streamflow CRPSS show catchments grouped by region (Fig. 1). All results are presented for a lead time of 5 days.

(Hogan et al., 2017). The coarse radiation grid results in warmer sea points being used to compute longwave fluxes applied over colder land points, causing too much cooling. This effect is seen for the temperature forecasts for winter 2014 and 2015 for the coastal catchments in Fig. 4b and c, in contrast to the inland catchment (Fig. 4a) which is less biased. The radiation resolution is improved in later model cycles (Hogan et al., 2017; Seierstad et al., 2016). In addition, the challenging steep coastal topography is not well represented by the spatial resolution in the ECMWF model (Seierstad et al., 2016). For inland catchments and the south and east regions, CRPSS shows that the uncalibrated $T_{\text {ens }}$ is skillful for both autumn and spring; hence, the calibration has a smaller effect in these catchments.

\subsection{Effect of temperature calibration for the streamflow forecast skill}

The skill of the temperature-calibrated streamflow ensemble forecasts, $Q_{\text {cal }}$, improved for most of the catchments for autumn, while both improved and reduced skill were seen for spring (Figs. 5-8). Autumn streamflow skill was improved by temperature calibration for all regions, the largest improvement was seen for the coast and the west and middle regions. Two possible explanations for this spatial pattern are (i) the improvement in temperature forecast skill during autumn in these regions and (ii) that many coastal catchments are more sensitive to the calibration of temperatures since the temperatures are more frequently around $0^{\circ} \mathrm{C}$ compared to the colder and dryer inland catchments. In spring, no clear spatial patterns are seen, neither for $Q_{\text {ens }}$ nor for the change in skill.

It is also evident that, independent of the sign of the temperature skill change (Fig. 5), a change in temperature has a 

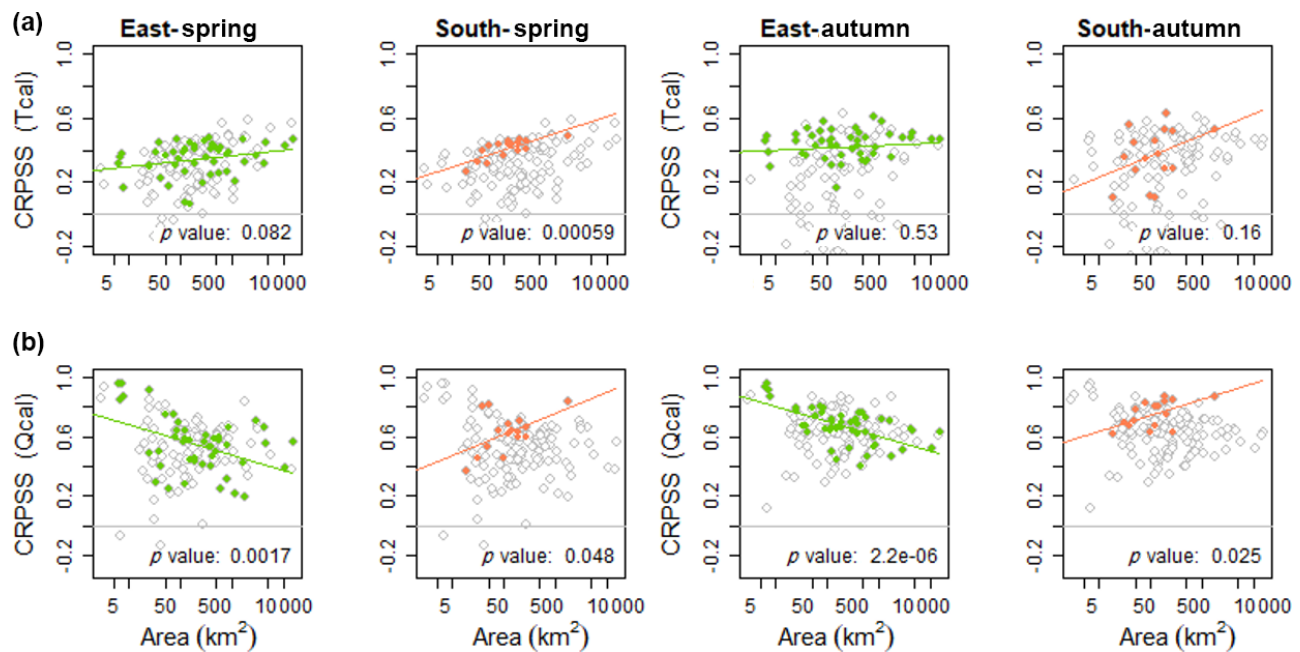

Figure 9. Temperature (row a) and streamflow (row b) CRPSS for the east (E) and south (S) regions, plotted as a function of catchment area for both autumn and spring. The colored dots show the CRPSS for the respective regions whereas the grey circles show the CRPSS for all 139 catchments. The linear regression line is plotted along with its $p$ value (significantly different from zero for $p$ values $<0.05$ ). All results are presented for a lead time of 5 days.

larger impact on streamflow in spring than in autumn. During spring, temperatures are often close to the two threshold temperatures that control the phase of precipitation and the onset of snowmelt. Such periods are challenging to simulate correctly (Engeland et al., 2010). Of additional importance, for spring as opposed to autumn, is the snow storage at the end of winter, as well as the snowmelt contribution to streamflow. Hence, estimated streamflow has a high sensitivity to changes in temperature during spring, a sensitivity also described for Alpine snow-covered catchments by Ceppi et al. (2013). Verkade et al. (2013), on the other hand, found only marginal effects of preprocessing temperature and precipitation for the streamflow skill in the Rhine catchments. The results presented herein and in the cited papers indicate that the effect of preprocessing depends on the hydrological regime (i.e., sensitivity to temperature), the initial skill of the forcing variables, and on which temporal periods (i.e., for specific events, seasons, or the whole year) the sensitivity is evaluated. The same lead time was used to relate improvement in streamflow to temperature; we consider this robust since most catchments in this study have a concentration time of less than a day.

In summary, it can be concluded that, to further improve streamflow forecasts during the snowmelt season, improved temperature forecasts are essential. Streamflow forecasts during spring have the highest potential for improvement since the temperature forecasts were not, for a majority of the catchments, improved by the applied calibration. For autumn, the substantial improvement in temperature forecast skill by grid calibration improves streamflow forecasts, but the sensitivity is less than for spring.

\subsection{Catchment characteristics and skill}

Only a few significant relationships between the catchment characteristics, e.g., catchment area and elevation gradient, and skill were found (Table 1). We expected to find the highest temperature skill in large catchments, due to averaging, and in catchments with small elevation differences, due to less elevation correction inaccuracy. No significant relationships between temperature skill and elevation difference were found for any combination of region or season. A positive relationship between temperature skill and catchment area was found for 5 out of 10 regression equations. This result is not conclusive, but indicates that (i) the smallest catchments are smaller than the grid size of the ECMWF model and therefore sensitive to the preprocessing and (ii) it is more challenging to forecast weather on small spatial scales than large spatial scales.

It was expected that streamflow skill would increase with catchment area due to averaging effects. Significant linear regression coefficients were found for east and south but with different signs, the same tendencies for both spring and autumn. The interpretation of this result is therefore ambiguous. For elevation difference, a significant negative correlation was found for 3 out of 10 datasets. This suggests that the downscaling approach has the potential to improve the streamflow forecasts. These results are not conclusive, and studies that are more detailed are needed to determine any significant relationships to catchment characteristics.

Forecasting in small catchments with particular characteristics may be challenging since they may not be well represented, neither by the numerical weather prediction model nor by the calibration methods. In our dataset, Foennerdalsvatn (Fig. 4c) is such an example. The catchment area is only 

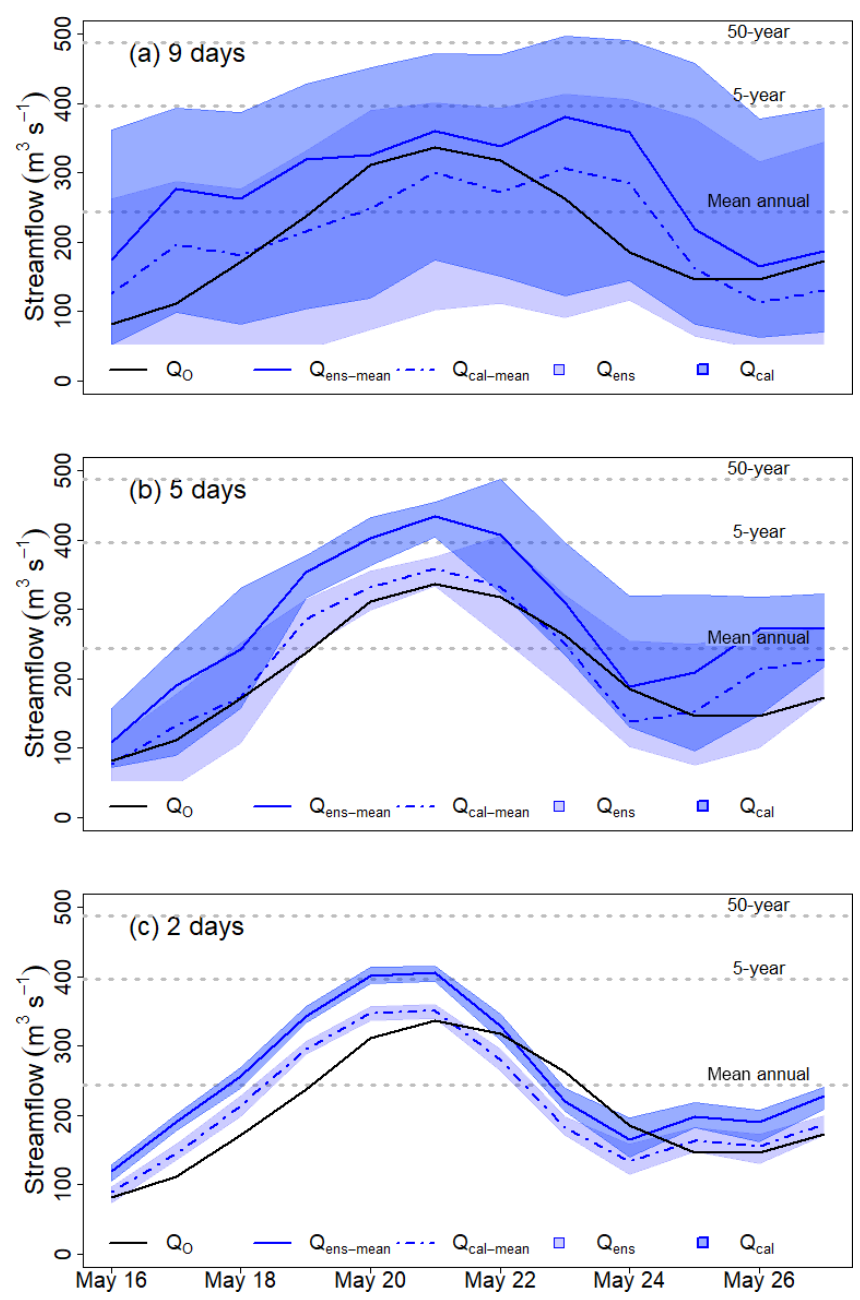

Figure 10. Forecasted streamflow for the Bulken catchment fort lead times of 9,5 , and 2 days. Forecast target dates on the $x$ axis, and streamflow $\left(\mathrm{m}^{3} \mathrm{~s}^{-1}\right)$ on the $y$ axis. Reference streamflow with seNorge observations $Q_{o}$ (black solid line), ensemble mean uncalibrated temperature $Q_{\text {ens }}$ (blue line), ensemble mean calibrated $Q_{\text {cal }}$ (blue dotted line), ensemble range $Q_{\text {ens }}$ (light violet area), and ensemble range $Q_{\text {cal }}$ (light blue area). The grey dotted lines indicate the thresholds for mean annual, 5-year, and 50-year floods.

$7.1 \mathrm{~km}^{2}$, elevation is high, topography is steep, glaciers cover $47 \%$ of the catchment area, and it is located close to the coast.

\subsection{Snowmelt flood 2013}

The snowmelt flood event (Fig. 10) illustrates clearly how temperature calibration affects forecasted ensemble streamflow. The increase in forecasted temperature by grid calibration results in additional snowmelt and thus increased streamflow. The increased streamflow led to a change in the warning level, from below to above the 5-year flood. For this event, however, the use of calibrated temperature reduced the performance of the forecasted streamflow, $Q_{\text {cal }}$. The refer- ence streamflow, $Q_{\mathrm{o}}$, is better captured by the streamflow forecasts based on uncalibrated temperature forecasts, $Q_{\text {ens }}$. The deterioration in the forecast performance using calibrated temperature is particular for this event. Other results provided in this study show clearly that the calibrated temperature ensembles improve the streamflow forecasts on average.

Figure 10 reveals how the ensemble range for the snowmelt event clearly increases with increasing lead time. For a lead time of 2 days (lower panel), the range is too narrow, while for a lead time of 9 days (upper panel), the wide forecasting intervals capture the events, but there is little information left in the forecasts.

\section{Summary and conclusion}

The main objective of this study was to investigate the effect of temperature forecast calibration on the streamflow ensemble forecast skill, as well as to identify potential improvements in the forecasting chain. We applied a gridded temperature calibration method and evaluated its effect on both temperature- and streamflow-forecasting skill. The seasonality in skill was evaluated and correlations to catchment characteristics and spatial patterns were investigated. Supported by the results presented in this paper, our answers to the research questions listed in the introduction are summarized as follows.

Are there seasonal effects of temperature calibration on the temperature ensemble forecast skill?

- The largest temperature skill improvements by calibration were found for poorly performing coastal catchments in autumn and winter.

- The effect of calibration on temperature skill was less clear in spring. In spring, the calibrated temperature resulted in reduced skill for many catchments.

- Smaller bias in spring explained a higher $T_{\text {ens }}$ skill and, hence, less room for improvements by calibration.

Are there seasonal effects of temperature calibration on the streamflow ensemble forecast skill?

- In autumn and winter, streamflow skill improved for most catchments. For spring, the calibration resulted in both better and worse skill.

- In spring, changes in temperature skill had a higher effect on streamflow skill, compared to autumn and winter.

Are there spatial patterns in the ensemble forecast skill and, if so, can these be related to catchment characteristics?

- The skill in temperature forecasts was the lowest in coastal catchments along the coast in the west, middle, 
and north in autumn, caused by a cold bias in the forecasts (this was also the case for winter, although these results are not shown).

- The largest improvement in skill for both temperature and streamflow was found for catchments with a cold bias in the temperature forecasts.

- A regional division seemed useful to identify spatial patterns in temperature forecasts, whereas for streamflow the spatial patterns were not so obvious.

- It was not possible to conclude a relationship between the catchment characteristics and skill.

Is streamflow affected by temperature calibration during a snowmelt flood?

- Streamflow increased by temperature calibration, changing the flood warning level, clearly showing the importance of correct temperature calibration for catchments with snow during snowmelt season.

This study showed that the applied gridded temperature calibration method improved the temperature skill for most catchments in autumn and winter. Temperature forecasts have an impact on streamflow and are important for seasons where temperature determines snowmelt and discriminates between rain and snowfall. The improvement in temperature skill propagated to streamflow skill for some, but not all, catchments. This was to a large degree dependent on region and the skill of the uncalibrated ensemble.

The most obvious improvement in the forecasting chain is to use the same temperature information, the seNorge temperature, for calibrating the temperature forecast that is used for calibrating the hydrological model, generating the initial conditions for the hydrological system, and evaluating the performance. In particular, the calibrated temperature forecast could be improved during spring when the streamflow forecasts are the most sensitive to temperature. The preprocessing of temperature includes both an elevation correction depending on lapse rate and the calibration method. Lapse rate in this study is defined as a constant, but actually depends on weather conditions, location, and elevation. In addition, the calibration method, here the quantile mapping, is sensitive to forecasted values outside the observation range, and other methods should be considered. In this study, we have investigated the isolated effect of uncertainties in temperature forecasts. For a more complete assessment of forecast uncertainties, error in initial conditions, hydrological model parameters, and structure need to be accounted for. In particular, we might expect a strong interaction between uncertainties in temperature forecasts and model parameters controlling snow accumulation and snowmelt processes.

The conclusions in this study are based on a testing period of almost 3 years. Even if this is a relatively short testing period, we believe that the large number of catchments to a large degree compensates for the short testing period and that the results and conclusions are therefore relatively robust. We suggest that some of the main conclusions can be valid for regions with a similar climate. The most important general conclusion is that streamflow forecasts are sensitive to the skill of temperature forecasts, especially in the snowmelt season. In addition, this study shows that reducing the cold temperature bias in coastal areas results in improved streamflow forecasts and that the preprocessing needs to account for seasonal differences in temperature forecasts (biases).

Data availability. Processed data are available by contacting the corresponding author. Raw meteorological data can be obtained from ECMWF (https://www.ecmwf.int/en/forecasts/ accessing-forecasts, last access: 1 February 2019).

Author contributions. TJH prepared the data, set up the forecasting chain (including writing new code for non-available functionalities), performed the data simulations and analysis, and wrote the manuscript. KE contributed to the writing. KE, IS, and LMT contributed to the design of the study, through giving advice during the work, and in the revision of the manuscript.

Competing interests. The authors declare that they have no conflict of interest.

Acknowledgements. The authors would like to thank Bård Grønbech at NVE for the work done with setting up the hydrological model for ensemble forecasting. We would like to thank Andrew Singleton at MET Norway for his comments during the work and proofreading of the manuscript. We thank Thomas Nipen and Ivar Seierstad at MET Norway for their support and for sharing their precipitation and temperature ensemble forecast calibration knowledge. In addition, their aid was valuable during the implementation of https://github.com/metno/gridpp (last access: 1 February 2019) in the forecasting chain. We also thank colleagues at NVE working on the project "Better uncertainty estimation in flood forecasting", led by Elin Langsholt.

We are also very thankful for in-depth reviews and valuable comments provided by Jan Verkade and three anonymous referees, as well as by Editor Jan Seibert. The review process helped improve the quality of the finished paper.

Edited by: Jan Seibert

Reviewed by: Jan Verkade and three anonymous referees

\section{References}

Aguado, E. and Burt, J. E.: Understanding weather and climate, 5th Edn., Upper Saddle River, NJ, USA, Pearson Prentice Hall, 2010. Beldring, S.: Distributed Element Water Balance Model System, report 4, 40 pp., Norwegian Water Resources and Energy directorate, Oslo, 2008. 
Bengtsson, L., Andrae, U., Aspelien, T., Batrak, Y., Calvo, J., de Rooy, W., Gleeson, E., Hansen-Sass, B., Homleid, M., Hortal, M., Ivarsson, K.-I., Lenderink, G., Niemelä, S., Nielsen, K. P., Onvlee, J., Rontu, L., Samuelsson, P., Muñoz, D. S., Subias, A., Tijm, S., Toll, V., Yang, X., and Køltzow, M. Ø.: The HARMONIE-AROME Model Configuration in the ALADINHIRLAM NWP System, Mon. Weather Rev., 145, 1919-1935, https://doi.org/10.1175/mwr-d-16-0417.1, 2017.

Bergström, S.: Development and application of a conceptual runoff model for Scandinavian catchments, Swedish Meteorological and Hydrological Institute SMHI, Report No. RHO 7, Norrköping, Sweden, 1976.

Bremnes, J. B.: Improved calibration of precipitation forecasts using ensemble techniques. Part 2: Statistical calibration methods, met.no, Report no. 4, 34 pp., Oslo, Norway, available at: http://met-xpprod.customer.enonic.io/ publikasjoner/met-report/met-report-2007 (last access: 1 February 2019), 2007.

Buizza, R.: Potential forecast skill of ensemble prediction and spread and skill distributions of the ECMWF ensemble prediction system, Mon. Weather Rev., 125, 99-119, https://doi.org/10.1175/15200493(1997)125<0099:PFSOEP>2.0.CO;2, 1997.

Buizza, R., Milleer, M., and Palmer, T. N.: Stochastic representation of model uncertainties in the ECMWF ensemble prediction system, Q. J. Roy. Meteor. Soc., 125, 2887-2908, https://doi.org/10.1002/qj.49712556006, 1999.

Buizza, R., Houtekamer, P. L., Pellerin, G., Toth, Z., Zhu, Y., and Wei, M.: Comparison of the ECMWF, MSC, and NCEP global ensemble prediction systems, Mon. Weather Rev., 133, 10761097, 2005.

Cloke, H. L. and Pappenberger, F.: Ensemble Forecasting: A review, J. Hydrol., 375, 613-626, 2009.

Ceppi, A., Ravazzani, G., Salandin, A., Rabuffetti, D., Montani, A., Borgonovo, E., and Mancini, M.: Effects of temperature on flood forecasting: analysis of an operative case study in Alpine basins, Nat. Hazards Earth Syst. Sci., 13, 1051-1062, https://doi.org/10.5194/nhess-13-1051-2013, 2013.

Dobrovičová, S., Dobrovič, R., and Dobrovič, J.: The Economic Impact of Floods and their Importance in Different Regions of the World with Emphasis on Europe, Proc. Econ. Financ., 34, 649655, https://doi.org/10.1016/S2212-5671(15)01681-0, 2015.

Doherty, J.: Calibration and Uncertainty Analysis for Complex Environmental Models, Watermark Numerical Computing, Brisbane, Australia, ISBN 978-0-9943786-0-6, 2015.

ECMWF: Set III - Atmospheric model Ensemble 15-day forecast (ENS), available at: https://www.ecmwf.int/en/forecasts/ datasets/set-iii (last access: 20 December 2018), 2018 a.

ECMWF: Changes in ECMWF models, available at: https: //www.ecmwf.int/en/forecasts/documentation-and-support/ changes-ecmwf-model (last access: 20 December 2018), 2018 b.

Engdahl, B. J. K. and Homleid, M.: Verification of experimental and Operational Weather Prediction Models December 2014 to February 2015, Norwegian Meteorological Institute, MetInfo (18/2015), Oslo, Norway, 2015.

Engeland, K., Renard, B., Steinsland, I., and Kolberg, S.: Evaluation of statistical models for forecast errors from the HBV model, J. Hydrol., 384, 142-155, 2010.
Evensen, G.: The Ensemble Kalman Filter: theoretical formulation and practical implementation, Ocean Dynam., 53, 343-367, 2003.

Gneiting, T., Raftery, A. E., Westveld III, A. H., and Goldman, T.: Calibrated Probabilistic Forecasting Using Ensemble Model Output Statistics and Minimum CRPS Estimation, Mon. Weather Rev., 133, 1098-1118, 2005.

Gneiting, T., Balabdaoui, F., and Raftery, A. E.: Probabilistic forecasts, calibration and sharpness, J. R. Stat. Soc. B, 69, 243-268, https://doi.org/10.1111/j.1467-9868.2007.00587.x, 2007.

Gottschalk, L., Jensen, J. L., Lundquist, D., Solantie, R., and Tollan, A.: Hydrologic Regions in the Nordic Countries, Hydrol. Res., 10, 273-286, 1979.

Hamill, T. M.: Interpretation of rank histograms for verifying ensemble forecasts, Mon. Weather Rev., 129, 550-560, 2001.

Hamill, T. M. and Colucci, S. J.: Verification of Eta-RSM ShortRange Ensemble Forecasts, Mon. Weather Rev., 125, 13121327, 1997.

Hamill, T. M.: Comments on "Calibrated Surface Temperature Forecasts from the Canadian Ensemble Prediction System Using Bayesian Model Averaging”, Mon. Weather Rev., 135, 42264230, https://doi.org/10.1175/2007mwr1963.1, 2007.

Hanssen-Bauer, I., Førland, E. J., Haddeland, I., Hisdal, H., Mayer, S., Nesje, A., Nilsen, J. E. Ø., Sandven, S., Sand $\varnothing$, A. B., and Sorteberg, A.: Climate in Norway 2100 - a knowledge base for climate adaption, Tech. Rep. 1, Norwegian Climate Service Centre, Oslo, Norway, 2017.

Hersbach, H.: Decomposition of the Continuous Ranked Probability Score for Ensemble Prediction Systems, Weather Forecast., 15, 559-570, https://doi.org/10.1175/15200434(2000)015<0559:dotcrp>2.0.co;2, 2000.

Hogan, R. J., Alhgrimm, M., Balsamo, G., Beljaars, A. C. M., Berrisford, P., Bozzo, A., Di Giuseppe, F., Forebes, R. M., Haiden, T., Lang, S., Mayer, M., Polichtchouk, I., Sandu, I., Vitart, F., and Wedi, N.: Radiation in numerical weather prediction Technical Memorandum: ECMWF, available at: https://www.ecmwf.int/en/elibrary/ 17771-radiation-numerical-weather-prediction (last access: 20 December 2018), 2017.

Jolliffe, I. T. and Primo, C.: Evaluating rank histograms using decompositions of the chi-square test statistic, Mon. Weather Rev., 136, 2133-2139, 2008.

Lafon, T., Dadson, S., Buys, G., and Prudhomme, C.: Bias correction of daily precipitation simulated by a regional climate model: a comparison of methods, Int. J. Climatol., 33, 13671381, https://doi.org/10.1002/joc.3518, 2013.

Langsrud, Ø., Frigessi, A., and Høst, G.: Pure model error for the HBV model, NVE, Hydra notat 4/98, 28 pp., Oslo, Norway, 1998.

Langsrud, Ø., Høst, G., Follestad, T., Frigessi, A., and Hirst, D.: Quantifying uncertainty in HBV runoff forecasts by stochastic simulations, NVE, Hydra notat 2/99, 38 pp., Oslo, Norway, 1999.

Leutbecher, M. and Palmer, T. N.: Ensemble forecasting, J. Comput. Phys., 227, 3515-3539, 2008.

Li, W., Duan, Q., Miao, C., Ye, A., Gong, W., and Di, Z.: A review on statistical postprocessing methods for hydrometeorological ensemble forecasting, WIRES Water, 4, e1246, https://doi.org/10.1002/wat2.1246, 2017. 
Mohr, M.: New routines for gridding of temperature and precipitation observations for "seNorge.no", met.no, Note no. 8, 40 pp., Oslo, Norway, 2008.

Müller, M., Homleid, M., Ivarsson, K.-I., Køltzow, M. A. Ø., Lindskog, M., Midtbø, K. H., Andrae, U., Aspelien, T., Berggren, L., Bjørge, D., Dahlgren, P., Kristiansen, J., Randriamampianina, R., Ridal, M., and Vignes, O.: AROME-MetCoOp: A Nordic Convective-Scale Operational Weather Prediction Model, Weather Forecast., 32, 609-627, https://doi.org/10.1175/waf-d16-0099.1, 2017.

Nash, J. E. and Sutcliffe, J. V.: River flow forecasting through conceptual models part I - A discussion of principles, J. Hydrol., 10, 282-290, https://doi.org/10.1016/0022-1694(70)90255-6, 1970.

Owens, R. G. and Hewson, T. D.: ECMWF Forecast User Guide, ECMWF, Reading, UK, https://doi.org/10.21957/m1cs7h, 2018.

Pagès, M. and Miró, J. R.: Determining temperature lapse rates over mountain slopes using vertically weighted regression: a case study from the Pyrenees, Meteorol. Appl., 17, 53-63, 2010.

Peel, M. C., Finlayson, B. L., and McMahon, T. A.: Updated world map of the Köppen-Geiger climate classification, Hydrol. Earth Syst. Sci., 11, 1633-1644, https://doi.org/10.5194/hess-11-16332007, 2007.

Persson, A.: User guide to ECMWF forecast products, edited by: Andersson, E. and Tsonevsky, I., ECMWF, Reading, UK, 2015.

Raftery, A. E., Gneiting, T., Balabdaoui, F., and Polakowski, M.: Using Bayesian model averaging to calibrate forecast ensembles, Mon. Weather Rev., 133, 1155-1174, 2005.

Rizzi, J., Nilsen, I. B., Stagge, J. H., Gisnås, K., and Tallaksen, L. M.: Five decades of warming: impacts on snow in Norway, Hydrol. Res., 49, 670-688, https://doi.org/10.2166/nh.2017.051, 2017.

Schaake, J., Pailleux, J., Thielen, J., Arritt, R., Hamill, T., Luo, L., Martin, E., McCollor, D., and Pappenberger, F.: Summary of recommendations of the first workshop on Postprocessing and Downscaling Atmospheric Forecasts for Hydrologic Applications held at Météo-France, Toulouse, France, 15-18 June 2009, Atmos. Sci. Lett., 11, 59-63, 2010.

Seierstad, I., Kristiansen, J., and Nipen, T.: Better temperature forecasts along the Norwegain coast, Newsletter, 148, available at: https://www.ecmwf.int/en/newsletter/148/ news/better-temperature-forecasts-along-norwegian-coast (last access: 1 February 2019), 2016.

Sheridan, P., Smith, S., Brown, A., and Vosper, S.: A simple heightbased correction for temperature downscaling in complex terrain, Meteorol. Appl., 17, 329-339, 2010.

Sælthun, N. R.: The Nordic HBV model, Norwegian Water Resources and Energy Administration Publication, 7, 1-26, 1996.

Tveito, O. E.: Spatial distribution of winter temperatures in Norway related to topography and large-scale atmospheric circulation, IAHS PUB Workshop, Brasilia, Brazil, 2002.
Tveito, O. E., Bjørdal, I., Skjelvåg, A. O., and Aune, B.: A GIS-based agro-ecological decision system based on gridded climatology, Meteorol. Appl., 12, 57-68, https://doi.org/10.1017/S1350482705001490, 2005.

Vannitsem, S., Wilks, D. S., and Messner, J. W. (Eds.): Statistical Postprocessing of Ensemble Forecasts, Elsevier, ISBN 9780128123720, https://doi.org/10.1016/B978-0-12-8123720.09988-X, 2018.

Verkade, J. S., Brown, J. D., Reggiani, P., and Weerts, A. H.: Post-processing ECMWF precipitation and temperature ensemble reforecasts for operational hydrologic forecasting at various spatial scales, J. Hydrol., 501, 73-91, https://doi.org/10.1016/j.jhydrol.2013.07.039, 2013.

Vormoor, K., Lawrence, D., Heistermann, M., and Bronstert, A.: Climate change impacts on the seasonality and generation processes of floods - projections and uncertainties for catchments with mixed snowmelt/rainfall regimes, Hydrol. Earth Syst. Sci., 19, 913-931, https://doi.org/10.5194/hess-19-913-2015, 2015.

Vormoor, K., Lawrence, D., Schlichting, L., Wilson, D., and Wong, W. K.: Evidence for changes in the magnitude and frequency of observed rainfall vs. snowmelt driven floods in Norway, J. Hydrol., 538, 33-48, 2016.

Wang, X. and Bishop, C. H.: Improvement of ensemble reliability with the new dressing kernel, Q. J. Roy. Meteor. Soc., 131, 965986, 2005.

Wetterhall, F., Pappenberger, F., Alfieri, L., Cloke, H. L., Thielendel Pozo, J., Balabanova, S., Danhelka, J., Vogelbacher, A., Salamon, P., Carrasco, I., Cabrera-Tordera, A. J., Corzo-Toscano, M., Garcia-Padilla, M., Garcia-Sanchez, R. J., Ardilouze, C., Jurela, S., Terek, B., Csik, A., Casey, J., Stankunavicius, G., Ceres, V., Sprokkereef, E., Stam, J., Anghel, E., Vladikovic, D., Alionte Eklund, C., Hjerdt, N., Djerv, H., Holmberg, F., Nilsson, J., Nyström, K., Sušnik, M., Hazlinger, M., and Holubecka, M.: HESS Opinions "Forecaster priorities for improving probabilistic flood forecasts”, Hydrol. Earth Syst. Sci., 17, 4389-4399, https://doi.org/10.5194/hess-17-4389-2013, 2013.

Wilks, D. S. and Hamill, T. M.: Comparison of Ensemble-MOS Methods Using GFS Reforecasts, Mon. Weather Rev., 135, 2379-2390, 2007.

Wilson, L. J., Beauregard, S., Raftery, A. E., and Verret, R.: Calibrated Surface Temperature Forecasts from the Canadian Ensemble Prediction System Using Bayesian Model Averaging, Mon. Weather Rev., 135, 1364-1385, https://doi.org/10.1175/MWR3347.1, 2007. 